\title{
Differences in pool-fire induced soot production between subcooled spray and flash boiling spray in a DISI engine
}

\author{
Mingli Cui ${ }^{1}$, Zhe Sun ${ }^{2}$, Hongyu Wang ${ }^{3}$, Xuesong Li ${ }^{* 4}$, David Hung ${ }^{5}$, Min Xu' \\ 1,2,3,4,6 School of Mechanical Engineering, Shanghai Jiao Tong University, Shanghai, China \\ ${ }^{5}$ University of Michigan-Shanghai Jiao Tong University Joint Institute, Shanghai Jiao Tong \\ University, Shanghai, China \\ Corresponding author email : xuesonl@sjtu.edu.cn
}

\begin{abstract}
Pool fire and fuel-rich combustion have been considered the primary soot/particulate matter sources for gasoline direct injection (GDI) engines, which is a crucial issue for commercial and passenger vehicles. Flash boiling atomization, achieved by heating the fuel before injection, can notably improve spray atomization and reduce the occurrence of pool fire, thus reduce soot emission under extreme conditions. This investigation compared the performance of subcooled spray combustions and flash boiling spray combustions with the use of an optical engine facility. The optical engine was equipped with an optical liner so that side views of the combustion can be captured with a high-speed color camera. The high-speed measurement data from early injection conditions were then analyzed with the HSV color model to investigate the flame characteristics in the premixed, infrared, and diffusion flame regions. Indicated mean effective pressure (IMEP) and particulate number (PN) under different conditions were also analyzed under different conditions. It was found that the combustion performance using flash boiling sprays is superior to that using subcooled sprays, and the difference between the two combustion modes was discussed with the use of the flame model.
\end{abstract}

\section{Keywords}

Gasoline direct injection engines; flash boiling sprays; PM emission; Hue model

\section{Introduction}

Gasoline direction injection (GDI) engines have been considered as one of the primary techniques for passenger cars because of the advantages of improving fuel economy and combustion efficiency [1]. Meanwhile, it is still desirable to enhance the thermal efficiency further and reduce the particulate matter (PM) emissions for spark ignition GDI engines [2, 3]. Fuel wall impingement and pool fire phenomenon can significantly worsen the combustion emission, which may be caused by improper injector design, unsuitable injection strategy, and extended spray penetration with downsized cylinder sizes, etc. [4-6]. Such pool fires are thought of as the primary reason for increased PM emissions and lower thermal efficiencies [7]. Techniques such as high-pressure injection and split/multiple fuel injectors can help soothe such deteriorated combustion phenomena $[8,9]$, while cannot completely address the issues caused by pool fires and film combustion [10].

Flash boiling atomization for fuel spray applications has been considered as a promising approach in addressing the issues from high-pressure injections via fierce phase change of the fuel [11-16]. Typically, flash boiling atomization would rely on increasing the temperature of the fuel or reducing the ambient pressure, so that the saturated fuel pressure is higher than the local pressure, leading to evaporation/boiling of the fuel. The micro-explosion mechanisms would benefit the fuel atomization process by producing finer droplets and more fuel vapor, thus reducing the interaction between the liquid fuel and the cylinder wall [17-19]. In the previous studies, it has been demonstrated that flash boiling atomization can reduce PN emissions under cold start conditions of IC engines [20, 21]. However, the mechanisms of 
such PN emission reduction is not clear yet. The impact of flash boiling atomization on the occurrence of pool fire is not thoroughly experimentally investigated either.

Furthermore, utilizing high-speed color cameras with image processing techniques in an optical engine can further explore the information from the flame images. More specifically, the emission spectrum information can be derived from color images captured by the highspeed camera. Gaydon et al. [22] reported that the emission in the near-ultraviolet regime (blue flame) mainly comes from fluorescence emission by four excited radicals $(\mathrm{OH} *(306.4$ $\mathrm{nm}), \mathrm{CH} *(431.5 \mathrm{~nm}), \mathrm{C} 2 *(516.5 \mathrm{~nm})$ and $\mathrm{CO} 2 *(340-650 \mathrm{~nm}))$. Generally, the emission with a longer wavelength indicates the radical emission mainly from soot that is frequently observed in diffusion flames. On the contrary, the blue region denotes relative complete combustion, and the emission with a shorter wavelength is resulted by premixed flame emissions, mostly from $\mathrm{CH}^{*}$ (centered at $430 \mathrm{~nm}$ ) and partially from C2 (centered at $518 \mathrm{~nm}$ ) $[23,24]$. By recategorizing the flame colors from flame measurements, information from different flame emission wavelengths can be identified and utilized to establish flame characteristics. Huang et al. [25-27] have performed a series of studies using HSV (Hue, Saturation, and Value) and RGB color models to process flame images for combustion process analysis. Our previous studies also used flame color models to study the flame propagation process in a signal cylinder engine equipped with an optical piston under flash boiling conditions. It was found from side-view flame measurement data that a larger premixed flame regime area was seen under flash boiling conditions, and the flame speed under flash boiling conditions was also faster. [28, 29]

In this research, we focus more on the pool fire from the wall/injector wetting phenomenon in comparison to typical engine flame propagation processes under regular combustion cycles. For such a purpose, a transparent cylinder was installed to study the pool fire from the side view. The pool fire produced under early-injection conditions (excess spray impingement) was investigated, and the effects of sub-cooled and flash boiling fuel injection schemes were analyzed.

\section{Experimental setup and Methods}

The engine conditions and specifications are summarized in Table 1. In this work, we used a four-stroke, single-cylinder optical engine for related investigations, and the experimental schematic is shown in Fig. 1. We used an optical liner and optical pent roof so that the soot generation process can be observed from the side view, with a high-speed color camera (NAC HX-5E). A metal piston was installed and applied in this optical engine. An 8-hole GDI Bosch injector was side-mounted to the engine head, and commercial gasoline (Octane No. 92, no ethanol-blended) was used as the fuel. To achieve flash boiling atomization and combustion in the optical engine, the fuel rail was heated by an external electric heater so that the fuel temperature. The temperature of the fuel line was monitored by thermocouples. The fuel temperature was set at $30 \pm 1{ }^{\circ} \mathrm{C}$ for the subcooled spray and $120 \pm 1{ }^{\circ} \mathrm{C}$ for the flash boiling spray $[18,20,21]$. The pressure sensor (KISTLER, 6125A, $\pm 2 \%$ ) combined with the combustion analyzer was used to record the in-cylinder combustion performance. Horiba MEXA 2300SCPS $( \pm 12 \%)$ was used for PN emission measurements. A sample flame measurement was also shown on the right-hand side of Figure 1. The injection timing was set at an early-injection $350^{\circ} \mathrm{bTDC}$ to simulate the serious impingement condition. Under this injection strategy, the fuel was impinged and generate a film on the piston top. Under the lowload low-speed condition, the fuel film will not be entirely evaporated till the ignition and the pool fire generated from that. The yellowish sooty flame on the piston top also proves that the pool fire exists, especially under subcooled spray conditions (such as in Figure1). The position of the fuel injector and the spark ignitor is demonstrated in Figure 1. Combustion around the 
injector can be readily captured through the pent roof window to identify potential combustion issues such as injector tip wetting.

Table 1 Engine specifications and experimental conditions

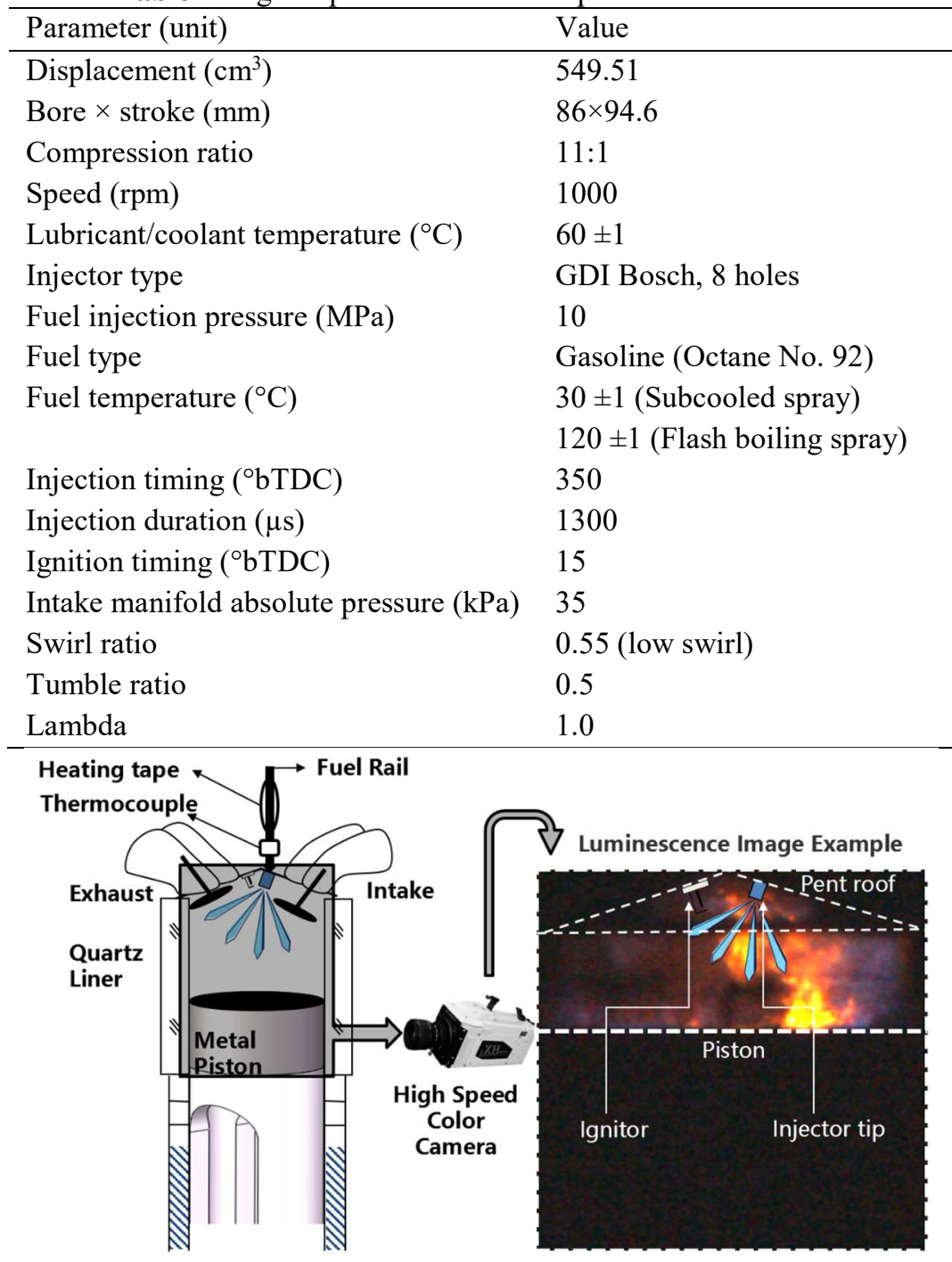

Figure 1. Optical arrangements for the optical engine measurements and definitions for the combustion images obtained from high-speed cameras.

Figure 2 depicts the image processing procedures with the color model method, as introduced previously. The measured RGB information was converted into entries in the HSV model, and the Hue information can be used to analyze the types of the flame. More information on the Hue analysis can be found in [25-27]. In this work, we selected and defined three different regions as follows: Region 1 includes Hue signal from $118-152^{\circ}$ and represents premixed combustion, and this region typically covers the blue-green color bands. Region 2 is in the range of $300-360^{\circ}$ and represents red to infrared wavelengths, and this region primarily represents the fuel pyrolysis process [25, 29, 30]. Finally, Region 3 covers the range from 0 $90^{\circ}$, which stands for the signal emitted from soot formation. The calibration and validation process can be found in [29]. A typical Hue decomposition of combustion inside the optical engine is also shown in Fig. 2. As can be seen, most of the yellowish, soot emissions were filtered out in Region 3, and some blue flame was also distinguished in Region 1, while most of the flame was in the pyrolysis region. It should be pointed out that the results from the HSV color model are predictive and qualitative at present because the calibration and identification are based on the burner flame. Therefore, it would be hard to identify the specific emission 
type or where the spectral wavelength peak locates of infrared flame in the engine combustion process, and more future work is required. Furthermore, more calibrations at a wider range of pressure and temperature also needed to quantify the results further. Also, it is hard to evaluate the self-absorption phenomena using the model. The flame emission distribution by the self-luminescence is affected by the line of sight in the in-cylinder combustion process. Thus, the spatial distribution of the flame is 2-D and has errors in the detailed hue caused by the superposition of light. Overall, the color model-based analysis still helps understand the combustion process better.

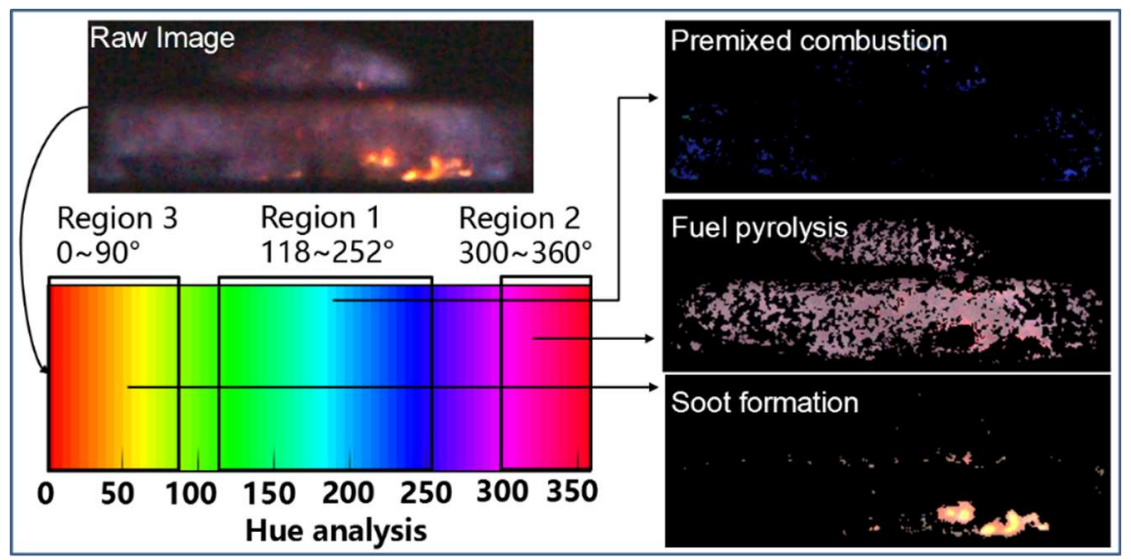

Figure 2. HSV color model decomposition definitions and sample flame decomposition results.

\section{Results and Discussion}

Figure 3 demonstrates the performance of the engine under both subcooled atomization conditions and flash boiling conditions, respectively. The results shown were averaged over 30 consecutive engine cycles. Panel (a) shows the peak pressure section from $-10^{\circ}$ to $60^{\circ}$ ATDC. As can be seen, the peak in-cylinder pressure under flash boiling combustion conditions is notably higher compared with sub-cooled conditions, which led to the increase of indicated mean effective pressure (IMEP) of the engine from 2.84 bar to 2.95 bar (4\% improvement). Measured particulate number (PN) emission is also reduced by $78 \%$ when flash boiling atomization is incorporated. Panel (b) and Panel (c) exhibit the normalized cumulative heat release rate and heat release rate curves as a function of crank angle degree, respectively. As can be seen, the peaked pressure under flash boiling conditions was shifted to an earlier engine timing than subcooled engine conditions. Panel (d) plots the integrated flame image intensity (converted to greyscale) over 30 cycles under flash boiling and subcooled conditions, respectively. It is worth noting that although the peak pressure under flash boiling conditions was notably higher than that under subcooled conditions, the maximum flame luminosity for the two cases was approximately the same. Such observations indicate that under subcooled conditions, there are more soot-related emissions captured by the camera, which did not contribute significantly to the expansion work of the engine.

we utilize the HSV color model to further analyze the color images obtained by the high-speed camera. Firstly, we incorporated the color model analysis to the data shown in Figure 3 Panel (d), and corresponding intensities in each region were plotted in Figure 4. As can be seen, the signal strength in Region 1 for both flash boiling and subcooled spray combustions were at the same level, indicating similar combustion characteristics in the premixed zone. For Region 2 (infrared zone), the signal strength of flash boiling combustion was higher than that under subcooled spray combustion, indicating stronger pyrolysis in flash boiling combustions. The infrared signal of subcooled spray combustions was weaker (maximum at a level of $4.0 \times 104)$, and its timing also shifted to a later engine crank angle. Finally, identified signal 
strength in Region 3 (diffusion flame zone) under flash boiling conditions was not remarkable, compared with that under subcooled conditions peaked at $50^{\circ}$ ATDC. As can be seen, although the total flame intensity were similar for flash boiling and subcooled spray combustions, they had distinctive flame compositions with respect to emission wavelengths and types of flames. The strong signal in Region 3 also indicated an enhanced soot production process at late engine timings. As shown in Figure 4, there exists a large fluctuation in the intensity variations of different regions. That proves that there are unsteady flames in different conditions, which caused by the pool fires.
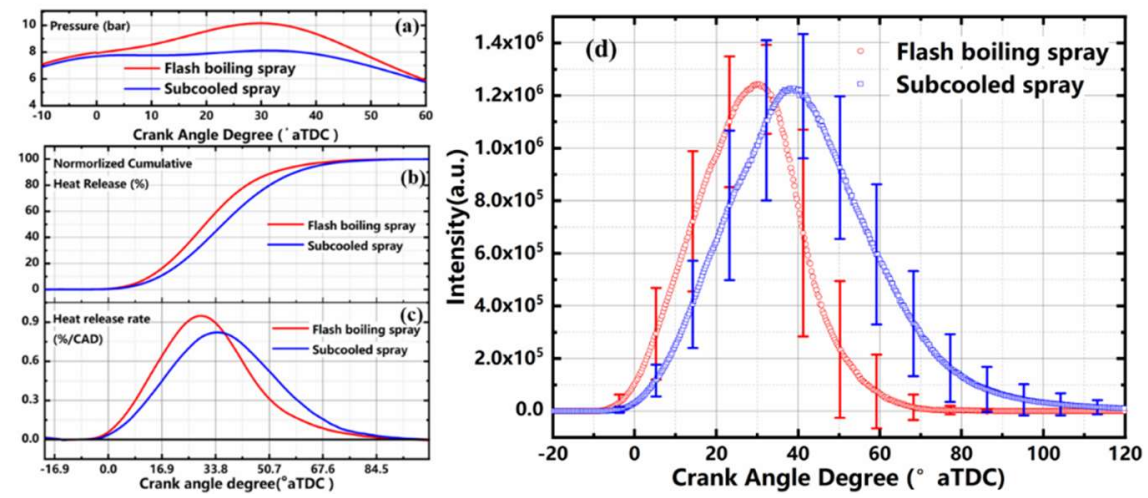

Figure 3. Optical engine combustion performance under subcooled conditions and flash boiling conditions. Panel (a). In-cylinder pressure as a function of crank angle degree. Panel (b). Normalized cumulative heat release as a function of crank angle degree. Panel (c). Heat release as a function of crank angle degree. Panel (d). Measured total flame intensity as a function of crank angle degree under subcooled conditions and flash boiling conditions.

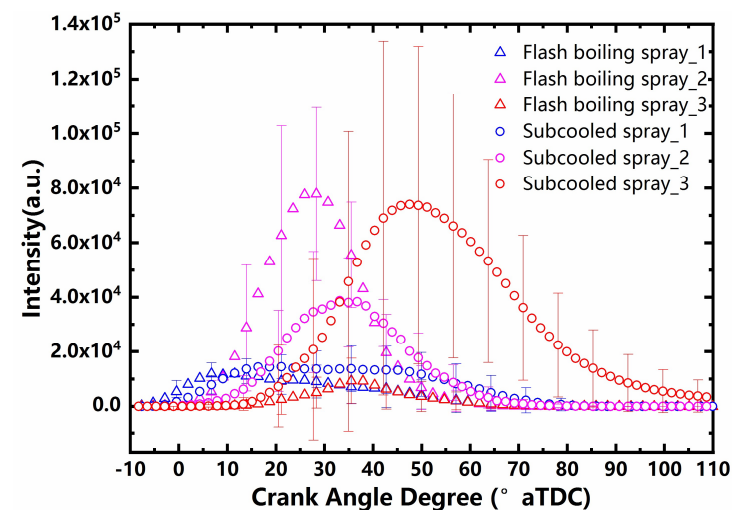

Figure 4. Flame regional intensity (with HSV analysis) as a function of crank angle degree under subcooled conditions and flash boiling conditions.

Figure 5 exhibits the averaged flame measurements from the side view under flash boiling conditions. The photos were averaged over 30 consecutive engine cycles at the same crank angle from $13^{\circ}$ ATDC to $49^{\circ}$ ATDC. As can be seen, although the optical engine was operated under early injection conditions (where impingements are likely), there was no evident sooty/diffusion flame near the piston; while there were notable yellow flame ligaments observed from the pent roof window, which is believed to be caused by film combustion from tip wetting. Furthermore, there were also sooty flames near the intake valve of the engine. It is held that because of the micro-explosion effects of the flash boiling spray near the fuel injector tip, the plume angle of the spray was enlarged, and the spray might interact with the intake valve, although the soot formation was not significant. Figure 5 also depicts the flame probability distribution at $49^{\circ}$ ATDC as the combustion was approximately finished. As can be seen, at this engine timing, the flame primary remained in the three zones noted in the figure, which are tip wetting zone (Zone 1), piston zone (Zone 2), and intake valve zone (Zone 3 ), respectively. Furthermore, as can be seen in the figure, the flame at $49^{\circ}$ ATDC was mostly in 
dark red, reflecting that even in the late combustion phase, the primary reactions within the cylinder was still not soot formatting process from sooty flames.

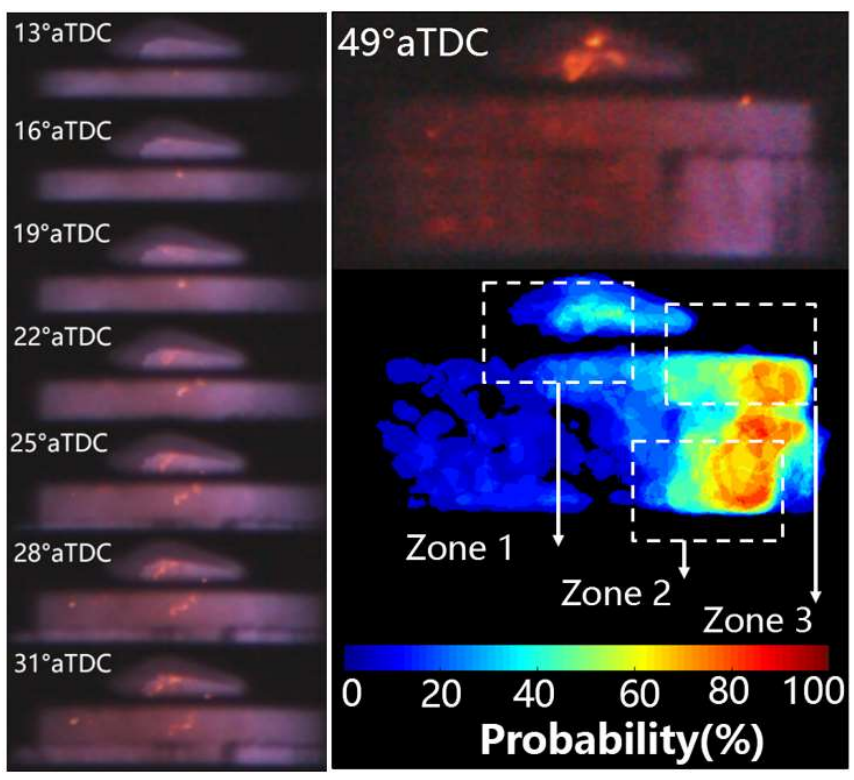

Figure 5. Averaged flame measurements from the side view of the engine under flash boiling conditions over 30 consecutive cycles. Flame occurrence probability was also shown in late combustion phases (49 ${ }^{\circ}$ ATDC).

We continue to analyze the combustion measurements under subcooled atomization from the side view. Figure 6 depicts such results, and the photos were averaged over 30 consecutive engine cycles at the same crank angle from $16^{\circ}$ ATDC to $64^{\circ}$ ATDC. An even later engine timing of $64^{\circ}$ ATDC was used since the pool fire is still visible at this timing. Compared with the color measurements under flash boiling conditions, it can be seen that a remarkable pool fire takes place on the metal piston in the experiments. Furthermore, from the sequential shots from $16^{\circ}$ ATDC to $64^{\circ}$ ATDC, it is well observed that the sooty flame firstly initiated from some flame filaments, then the size of the pool fire enlarged and lasted for a long period, which suggests the mechanisms and impacts of the pool fire. Finally, we also used the zones demonstrated in Fig. 6 for probability analysis, and it is seen that there was still a high flame probability in the three zones, (tip wetting zone, piston zone, and intake valve zone) at $49^{\circ}$ ATDC, yet this time the flame signal at the zone near the piston dominated. This trend lasted and strong flame probability can still be seen near the piston at $64^{\circ}$ ATDC.

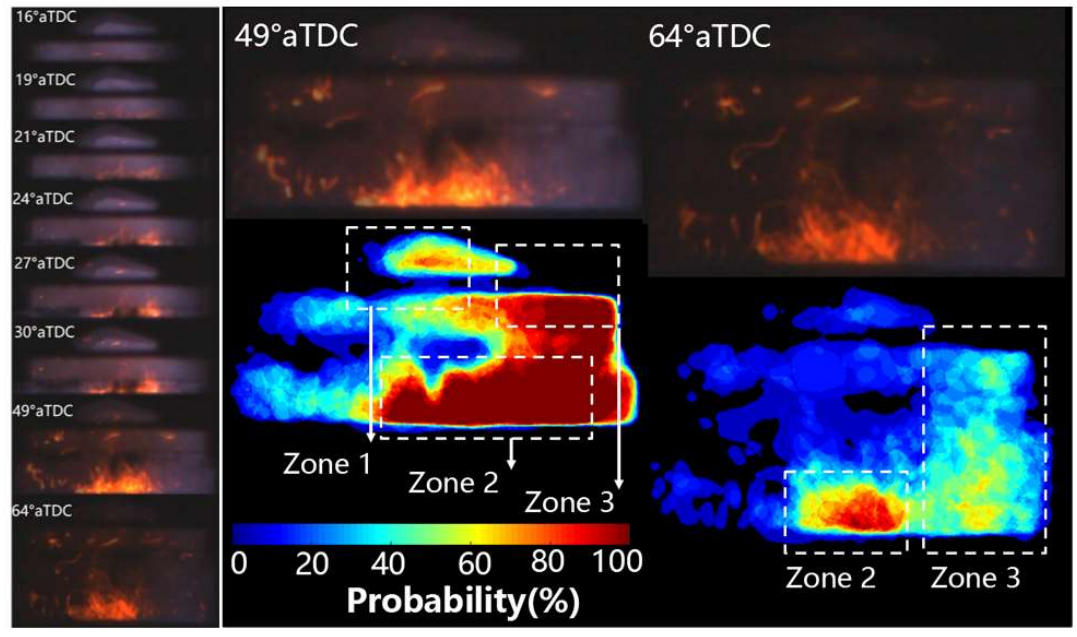


Figure 6. Averaged flame measurements from the side view of the engine under subcooled conditions over 30 consecutive cycles. Flame occurrence probability was also shown in late combustion phases $\left(49^{\circ}\right.$ ATDC and $64^{\circ}$ ATDC).

\section{Conclusions}

The differences in pool-fire induced soot formation between subcooled spray and flash boiling spray in a DISI engine were investigated under early injection conditions in this work. The following conclusions are reached in this investigation:

1) The flash boiling spray combustion showed higher in-cylinder peak pressure, higher IMEP (4\% increase), lower $\mathrm{COV}_{\text {imep }}$ (reduced cyclic variation), shorter ignition delay, and advanced combustion phasing compared to subcooled. Meanwhile, the measured PN emissions reduced by $78 \%$ under flash boiling combustion compared to subcooled.

2) Significant pool fire took place on the metal piston under subcooled injection and continued for a prolonged period until the late burn phase at 64-70 ATDC, which contributes significantly to soot formations. However, flash boiling suppressed pool fire, and no sooty flames were noted near the piston. The probability of flame existence at the late combustion phase within tip wetting zone, piston zone, and intake valve was significantly reduced under flash boiling compared to subcooled. Soot formation under flash boiling conditions could be related to tip-wetting, although it still has a lower occurrence probability compared to that of subcooled.

3) The HSV color model and flame color intensity analysis showed that both flash boiling and subcooled spray combustions indicated similar intensities in the premixed flames, which means similar premixed burn characteristics. The infrared signal strength under flash boiling was much higher than that of subcooled, indicating stronger fuel pyrolysis under flash boiling. Meanwhile, the signal that identifies the diffusion flame zone (soot formation) was not remarkable under flash boiling conditions compared to subcooled conditions that showed a peak at $50^{\circ}$ ATDC.

4) Flames under subcooled conditions exhibited bright yellow cores representing developed soot aggregates. Flames under flash boiling conditions showed dark red flames zones, which is likely to be associated with soot precursors that easier to be oxidized.

\section{Acknowledgments}

This work was sponsored by the National Natural Science Foundation of China (Grant No. 51876126/E060502) and the Shanghai Pujiang Program (Grant No. 18PJ1406200). The investigation was carried out at the National Engineering Laboratory for Automotive Electronic Control Technology, Shanghai Jiao Tong University.

\section{Nomenclature}

\begin{tabular}{|llll|}
\hline a.u. & Arbitrary unit & $\mathrm{H}_{2}$ & Hydrogen \\
aTDC & After top dead center & HSV & Hue, Saturation, and Value \\
bTDC & Before top dead center & IC & Internal combustion \\
CAD & Crank angle degree & IMEP & Indicated mean effective pressure \\
$\mathrm{CH}$ & Hydrocarbon & $\mathrm{OH}$ & Hydroxyl radical \\
$\mathrm{CO}_{2}$ & Carbon dioxide & $\mathrm{PM}$ & Particulate matter \\
$\mathrm{COV}$ & Coefficient of variance & PN & Particulate number \\
DISI & Direct injection spark ignition & RGB & Red, Green, Blue \\
GDI & Gasoline direct injection & TEM & Transmission electron microscopy \\
\hline
\end{tabular}




\section{References}

1. Zhao, F., M.C. Lai, and D.L. Harrington, Automotive spark-ignited direct-injection gasoline engines. Progress in Energy and Combustion Science, 1999. 25(5): p. 437-562.

2. Gong, C., et al., Comparative study on combustion and emissions between methanol port-injection engine and methanol direct-injection engine with $\mathrm{H} 2$-enriched port-injection under lean-burn conditions. Energy Conversion and Management, 2019. 200: p. 112096.

3. Gong, C., et al., Assessment of ultra-lean burn characteristics for a stratified-charge direct-injection sparkignition methanol engine under different high compression ratios. Applied Energy, 2020. 261: p. 114478.

4. Drake, M.C., et al., Piston Fuel Films as a Source of Smoke and Hydrocarbon Emissions from a WallControlled Spark-Ignited Direct-Injection Engine. SAE Transactions, 2003. 112: p. 762-783.

5. Serras-Pereira, J., P.G. Aleiferis, and D. Richardson, Imaging and heat flux measurements of wall impinging sprays of hydrocarbons and alcohols in a direct-injection spark-ignition engine. Fuel, 2012. 91(1): p. 264-297.

6. Chin, S.T. and C.F.F. Lee, Numerical investigation of the effect of wall wetting on hydrocarbon emissions in engines. Proceedings of the Combustion Institute, 2002. 29(1): p. 767-773.

7. Velji, A., et al., Investigations of the Formation and Oxidation of Soot Inside a Direct Injection Spark Ignition Engine Using Advanced Laser-Techniques. Sae Technical Papers, 2010. 2010-01-0352.

8. Duan, X., et al., Quantitative investigation the influences of the injection timing under single and double injection strategies on performance, combustion and emissions characteristics of a GDI SI engine fueled with gasoline/ethanol blend. Fuel, 2020. 260: p. 116363.

9. Potenza, M., M. Milanese, and A. de Risi, Effect of injection strategies on particulate matter structures of a turbocharged GDI engine. Fuel, 2019. 237: p. 413-428.

10. Su, J., et al., Particle Number Emissions Reduction Using Multiple Injection Strategies in a Boosted SparkIgnition Direct-Injection (SIDI) Gasoline Engine. Sae International Journal of Engines, 2014. 8(1): p. 2029.

11. Zeng, W., et al., Macroscopic characteristics for direct-injection multi-hole sprays using dimensionless analysis. Experimental Thermal and Fluid Science, 2012. 40: p. 81-92.

12. Zeng, W., et al., Atomization and vaporization for flash-boiling multi-hole sprays with alcohol fuels. Fuel, 2012. 95: p. 287-297.

13. $\mathrm{Li}, \mathrm{X} ., \mathrm{T} . \mathrm{Li}$, and M. Xu, Effect of ambient temperature on flash-boiling spray characteristics for a multihole gasoline injector. Experiments in Fluids, 2019. 60(7): p. 109.

14. Li, X., et al., Investigations on near-field atomization of flash boiling sprays for gasoline direct injection related applications. Fuel, 2019. 257: p. 116097.

15. Yang, S., et al., A review on the experimental non-intrusive investigation of fuel injector phase changing flow. Fuel, 2020. 259: p. 116188.

16. $\mathrm{Xu}, \mathrm{Q}$., et al., Investigation of two-hole flash-boiling plume-to-plume interaction and its impact on spray collapse. International Journal of Heat and Mass Transfer, 2019. 138: p. 608-619.

17. G. Zhang, M.X., Y. Zhang, M. Zhang, and D.J. Cleary, Macroscopic characterization of flash-boiling multihole sprays using planar laser induced exciplex fluorescence technique. Part i. On-axis spray structure. Atomization and Spray, 2012. 22(10) : p. 861-878.

18. Xu, M., et al., Flash Boiling: Easy and Better Way to Generate Ideal Sprays than the High Injection Pressure. SAE International Journal of Fuels and Lubricants, 2013. 6(1): p. 137-148.

19. Wu, S., et al. Analyzing the cycle-to-cycle variations of vapor and liquid phases of evaporating SIDI sprays via proper orthogonal decomposition technique. 2015.

20. Yang, J., et al., Influence of flash boiling spray on the combustion characteristics of a spark-ignition directinjection optical engine under cold start. Combustion and Flame, 2018. 188: p. 66-76.

21. Dong, X., et al., Effects of flash boiling injection on in-cylinder spray, mixing and combustion of a sparkignition direct-injection engine. Proceedings of the Combustion Institute, 2019. 37(4): p. 4921-4928.

22. Gaydon, A.G., The Spectroscopy of Flames (London: Chapman and Hall). The Spectroscopy of Flames (London: Chapman and Hall). 1974.

23. N, B.J.A.B.J., Flame and Combustion 1985.

24. P, C.T., Studies of $\mathrm{OH}, \mathrm{CO}, \mathrm{CH}$ and $\mathrm{C} 2$ radiation from laminar and turbulent propane-air and ethyleneair flames. NACA Technical Report, 1958.

25. Huang, H.-W. and Y. Zhang, Flame colour characterization in the visible and infrared spectrum using a digital camera and image processing. Measurement Science and Technology, 2008. 19(8).

26. Huang, H.W. and Y. Zhang, Dynamic application of digital image and colour processing in characterizing flame radiation features. Measurement Science and Technology, 2010. 21(8).

27. Huang, H.W. and Y. Zhang, Analysis of the ignition process using a digital image and colour processing technique. Measurement Science and Technology, 2011. 22(7).

28. Sun, Z., et al., Study of Flash Boiling Spray Combustion in a Spark Ignition Direct Injection Optical Engine Using Digital Image Processing Diagnostics. 2019, SAE International.

29. Sun, Z., et al. Flame Emission Characteristics in a Direct Injection Spark Ignition Optical Engine Using Image Processing Based Diagnostics. in ASME 2018 Internal Combustion Engine Division Fall Technical Conference. 2018.

30. Wang, Y., et al., Investigation of ignition process from visible to infrared by a high speed colour camera. Fuel, 2016. 185: p. 500-507. 